\title{
HISTÓRIAS DE CRUZAMENTOS POLÍTICOS E AFETIVOS ENTRE AMÉRICA LATINA E ÁFRICA
}

\author{
Alexsandro de Sousa e Silva ${ }^{1}$
}

Resenha de: BASUlTO, Sergio; CONTRERAS, Dalmiro; GLISSER, Mario. Chilenos en Mozambique. Experiencia de solidaridad y amistad entre dos pueblos. Santiago de Chile: Ceibo, 2013 (Colección Memorias e Crónicas).

O livro Chilenos en Mozambique reúne testemunhos de exilados e exiladas do Chile que viveram anos, e mesmo décadas, no país africano. Trata-se de uma grande contribuição aos estudos acadêmicos por trazer uma miríade de realidades e vivências inacessível aos pesquisadores. Além de textos introdutórios, a obra é composta por quarenta e sete relatos, em sua maioria de chilenos e chilenas que viveram em Moçambique desde os anos 1970. Trata-se de pessoas que viveram no exílio desde o início da ditadura de Augusto Pinochet no Chile em 1973, quando o regime autoritário perseguiu membros e simpatizantes do governo socialista de Salvador Allende ${ }^{1}$. Dentre os participantes da publicação, também há filhos e filhas de exilados e exiladas (que recordam sua infância em África), um brasileiro (Sergio Bacchi, décimo relato) e um argentino (Carlos Schugurensky, trigésimo sétimo relato), além de relatos póstumos.

A presença de estrangeiros em Moçambique foi possível devido ao empenho do governo da Frente de Libertação de Moçambique (Frelimo), em especial do presidente Samora Moisés Machel (1975-1986), em trazer técnicos e intelectuais para ocupar postos de trabalho abandonados e recuperar maquinários destruídos por portugueses colonialistas em fuga. Após 500 anos de exploração colonial, o país não tinha em seus quadros no momento de sua independência (1975) a quantidade necessária de especialistas em funções essenciais para a administração geral em suas diferentes áreas (saúde, educação e economia, principalmente). Graças ao "Convênio de cooperação técnica com o Partido Frelimo" estabelecido entre o movimento político moçambicano e o Partido Comunista chileno (PCCh) em 1977 na Argélia, famílias exiladas que se encontravam dispersas pelo mundo começaram a migrar para o país africano. Essas pessoas estavam numa fase do exílio em que, após dois anos de ditadura, reconheceram a persistência e a durabilidade do governo pinochetista, constatando dessa forma a dificuldade em retornar ao lar e a necessidade de sobrevivência no exterior. Além do mencionado convênio entre a Frelimo e o PCCh, vale destacar a mediação de grupos políticos, familiares e amigos para levarem exilados a Moçambique (Prefácio, p. 17).

${ }^{1}$ As cifras de exilados e exiladas do Chile entre 1973 e 1990 permanece incerta e varia entre 200.000 a 4000.000 pessoas. Cf. REBOLLEDO, Loreto. Memorias del desarraigo. Testimonios de exílio y retorno de hombres y mujeres de Chile. Santiago de Chile: Catalonia, 2006, p. 29-31.

1 Bacharel e Licenciado em História pela Universidade de São Paulo. Mestre e doutorando em História Social na mesma instituição. E-mail: alexsandro.dses@gmail.com. 
A comunidade chilena em Moçambique foi pequena se comparada às presentes em outros países de asilo, como México, França e Suécia: cerca de 500 exilados e exiladas, chamados e chamadas de cooperantes no país. A característica principal do grupo era a alta qualificação profissional, em geral com curso superior e experiência nas respectivas áreas de atuação no Chile e no exterior. Como exemplo, mencionemos os casos dos compiladores do livro. Sergio Basulto (primeiro relato) era médico veterinário e após o golpe de Estado no Chile em 1973 foi trabalhar na Noruega; uma vez em Moçambique, foi diretor nacional da atividade pesqueira. Dalmiro Contreras (era relato), contador, trabalhou na Unidade Popular chilena (UP) e após o início da ditadura passou pela Argentina e República Democrática Alemã (RDA); na África, apoiou o Ministério de Finanças e o Banco de Moçambique, além de ajudar na criação de estatais e formação de funcionários. Enfim, Mario Glisser (décimo sexto relato) escapou do Chile ditatorial, esteve três anos em Israel e no jovem país africano trabalhou em hospitais atendendo a crianças e treinando novos profissionais na área. Estes três exemplos dão o tom geral das ricas trajetórias destes profissionais, expostas no livro.

Apesar da diversidade de experiências, os relatos nos permitem construir um painel geral sobre o exílio dos chilenos em Moçambique. Muitos entrevistados e entrevistadas recordam o labor no Chile e a saída para o exílio. Uma vez fora do país de origem, surge a dificuldade de se manter no país de acolha, pois a continuidade da carreira no exterior, disputando espaço com cidadãos formados e empregados, é um dos maiores desafios de um exilado ou exilada. Assim relata Patricio Miranda (vigésimo quinto relato): "Conocí a uno que, en un país desarrollado, hacía el aseo de los cines terminadas las funciones" (p. 215). Por isso esse advogado, assim como os demais técnicos e técnicas que vieram a Moçambique, sentia-se privilegiado por seguir suas atividades profissionais.

A viagem e a chegada a Moçambique marcaram muitos depoimentos. A visão da África que os entrevistados e as entrevistadas tinham antes de viajarem se chocou com a realidade vivida. Claudio Contreras (quarto relato), educador e historiador, diz que seu conhecimento sobre o continente se limitava ao apartheid sul-africano, "documentales sobre su fauna y algo de sus costumbres y culturas tradicionales" e ao personagem Tarzan (p. 64). As notícias internacionais sobre Angola e Moçambique que chegavam à Noruega nos anos 1970 causavam temor nos amigos de Sergio Basulto (primero relato), os quais o aconselharam a não aceitar o empregado na África:

Seguramente con la mejor intención, para que yo desistiera de lo que ellos consideraban mi aventura africana. No pasaría mucho antes que algunos de ellos llegaran a colaborar animosamente a Mozambique (p. 26).

O desconhecimento dos imigrantes sobre a África é contrastado com o conhecimento que os africanos tinham da América: assim lemos sobre o espanto da psicóloga Silvia Quiroga (vigésimo oitavo relato), que nada conhecia de Moçambique enquanto o taxista mostrava saber a história do Chile (p. 245). Esse desencontro permanece como um problema até nosso dias: o prefácio do livro mostra imprecisões com a história africana, esquecendo-se de falar de Guiné-Bissau e demarcando a "caída de Salazar" no ano de 1974 (p. 16). Alguns protagonistas relatam ao longo da obra que, desde as escalas durante o voo, começaram a sentir novas sensações, como o relatou a desenhista Cristina Pacheco (vigésimo sétimo relato) quem registrou as primeiras impressões (como o calor excessivo) quando passou pelo então Zaire (atual República Democrática do Congo) vindo do Canadá, onde estava refugiada.

O período de adaptação no país oscilou entre a dificuldade de aprender os novos códigos sociais e a identificação com as sociedades moçambicanas. A primeira estada normalmente foi em hotéis de Maputo, em especial o Avis (simbolicamente localizado entre 
as avenidas Patrice Lumumba e Salvador Allende), Turismo e Cardoso, durante as primeiras semanas. Em seguida, geralmente as famílias chilenas mudavamse para casas residenciais; voltaremos adiante a esse tema. Muitas das crianças que vieram a Moçambique estudaram na Escola Internacional, onde ficavam os filhos e as filhas dos e das cooperantes.

Durante o processo de convivência em Moçambique, o desencontro linguístico é um tema muito presente nos relatos. Cristina Pacheco (vigésimo sétimo relato) afirma que teve que recorrer ao portuñol para se comunicar com seus novos amigos (p. 230). Mario Glisser (décimo sexto relato) aprendeu expressões em ronga e changana, pois seus pacientes não falavam português (p. 153-154). Ao longo de todo o livro, muitas palavras citadas em português são "espanholizadas" ou apresentam problemas de acentuação, pois alguns sinais são inexistentes no idioma materno dos autores e das autoras: Simoes, guía, Independencia, continúa, Joao, Sebastiao, quarteirao, Construçâo, Aguas, Libertaçâo, Direçâo, Perdigâo, relatorios, Creçe (creche), Cámara, português, escritorio, camarâo, Vovô (vovó, abuela), entre outros. A persistência da estranheza de nós, nativos de Língua Portuguesa, em escrever em espanhol e vice-versa (hispanohablantes al escribir en portugués) mostra o quanto estamos distantes da América Latina em nossa convivência cultural e intelectual, diante do imperativo em dialogar com as produções em inglês e francês. Não vamos falar aqui da nossa relação com as línguas africanas e ameríndias para não ficarmos presos na questão linguística mais geral, que deve ser enfrentada pela comunidade acadêmica com maior seriedade, a nosso ver.

Os trabalhos dos e das cooperantes foram realizados e, à medida que os projetos avançavam, os problemas iniciais iam ficando para trás. A princípio, os recém-chegados e recém-chegadas duvidavam da própria capacidade de lidar com o desafio proposto pelo governo. Diante da precariedade que os técnicos encontraram nos postos de serviço, a solidariedade, a criatividade e a persistência foram as ferramentas utilizadas para superação dos entraves. O geólogo Iván Escobar (décimo primeiro relato) mandou construir instalações visando a melhoria de vida dos trabalhadores de uma mina de cobre na fronteira com a Rodésia/Zimbabwe (p. 123-124). Trabalhava-se até nos finais de semana e fora de horário de serviço para atender a demandas oficiais, como foi o caso de Cristina Pacheco (vigésimo sétimo relato, p. 235), tamanho o empenho e entrega de muitos entrevistados e entrevistadas. Os dois maiores destaques entre os relatos foi a elaboração de móveis simples "Unidad Popular”, por parte de Verónica Urzúa (quadragésimo relato) e, segundo algumas memórias (Carlos Schugurenski, trigésimo sétimo relato, Luis Alvarado, quadragésimo quinto), o sucesso da construção de um aparelho de rádio, chamado Xirico em referência ao tradicional pássaro, e sua difusão pelo país, contribuindo para maior alcance dos discursos oficiais, notícias e músicas no país. Por outro lado, também há frustrações, como a experiência da arquivista Wenke Adam (quadragésimo primeiro relato), encarregada de manter um aparelho de fotocópias funcionando, dada a precariedade em seu lugar de trabalho (p. 358359).

Espaços de sociabilidade foram se construindo em Moçambique. A presença de estrangeiros (soviéticos, europeus e latino-americanos, em especial cubanos e brasileiros) e o convívio com diferentes nações africanas no país fez com que muitos chilenos e chilenas convivessem com o cosmopolitismo. As visitas entre as novas amizades reforçaram os recentes e os antigos laços de amizade, conforme vemos no relato da representante da Unicef Marta Mauras (vigésimo quarto relato), que recebia frequentemente em casa conterrâneos e estrangeiros (p. 210). O grupo musical Araucaria reuniu alguns desses exilados e exiladas cantando em espanhol e português, mantendo a identidade nacional (mesma função da "escuela chilena" que a psicóloga Manuela García, décimo quarto relato, frequentava aos sábados) ao mesmo tempo em que interagiam com as culturas locais na Peña Palhota, que reunia adeptos do Canto 
Nuevo (corrente musical surgida em meados dos anos 1970, herdeira da Nueva Canción Chilena) com "danzas guerreras bantúes" (Antonio García, décimo quinto relato, p. 148). Também havia o conjunto folclórico Paloma Anahí (Silvia Quiroga, $28^{\circ}$ relato, p. 247). Esse hibridismo na esfera cultural também se estendeu ao religioso, conforme depoimento da escritora Gloria Liberman (vigésimo terceiro relato).

Com o avanço das guerras da Frelimo contra a Resistência Nacional Moçambicana (RENAMO), grupo paramilitar financiado pela África do Sul e Estados Unidos da América, nas proximidades de Maputo aumentava também a dificuldade em seguir com o trabalho e o convívio no país em meados dos anos 1980. O engenheiro comercial Leo Clares (segundo relato) fala em "permanentes estados de toque de queda y vigilancia militar" (p. 47); Delfina Ode (vigésimo sexto relato), economista, reconheceu ter como principal motivo de saída a intensidade da guerra em 1989 (p. 226). No Chile, diante da pressão social em 1983 e da crise econômica que colocou em cheque o neoliberalismo avassalador dos "Chicago Boys", os generais foram obrigados a conceder uma pequena abertura política que possibilitou o retorno de milhares de exilados e exiladas. Leo Clares retornou com a família para a América por causa das listas de "autorizados" que os militares chilenos publicavam (p. 58). O duplo contexto fez com que a comunidade chilena em Moçambique começasse a diminuir. As despedidas e os agradecimentos pela vivência em África davam o tom final da maioria dos relatos.

O mapa geral do que foi a experiência exílica dos chilenos e das chilenas em Moçambique que traçamos acima é constituído por momentos de fraternidade, mas também de tensões. As narrações retratam a condição privilegiada dos cooperantes, vista a precariedade com que os pobres viviam após séculos de exploração colonial. O historiador Claudio Contreras (quarto relato) afirma que "si bien compartíamos las dificultades de desabastecimiento, de falta de agua o de luz, de alguna manera me sentía en un grado de privilegio: no me faltaba mi familia o al menos tenía algo para desayunar" (p. 67). Antonio García (décimo quinto relato), antropólogo, foi mais categórico por sua vez: "nuestro círculo más próximo de amigos siempre fueron los que compartían nuestro color de piel y aquellos mozambicanos que tenían suerte de tener más recursos y vivir en el ambiente más próximo" (p. 150). Por outro lado, alguns participantes do livro expõem momentos de dificuldades, compartilhando os momentos difíceis com a população, como foi o caso de Cristina Pacheco (vigésimo sétimo relato): “teníamos una tarjeta para mercadería cada 15 días, debíamos hacer cola (bicha) y muchas veces ocurrió que casi al llegar al mesón, decían: 'acabó', 'no hay más"' (p. 231).

Dois aspectos ressaltam a questão do privilégio dos e das cooperantes: as moradias requintadas onde os exilados e exiladas viviam com suas famílias e os relatos sobre os empregados e empregadas. O técnico brasileiro Sergio Bacchi (décimo relato) morava com a esposa Selva Aída Eidelstein ao lado do Palácio de Governo (p. 114); a música Andrea Laborde (vigésimo primeiro relato) morou com família em frente à instituição. O engenheiro florestal Jaime Tohá (trigésimo oitavo relato) residiu em uma "hermosa casa" e depois mudou com a família para um "hermosísimo chalet" (p. 328, 331). Iván Escobar (décimo primeiro relato), geólogo, havia solicitado um empregado e dois guardas (o Governo queria oferecer quatro) para a casa no norte do país, que era um "lujo" (p. 121-123). Lemos ao longo do livro diversos agradecimentos aos empregados e empregadas que trabalharam para os entrevistados e entrevistadas. A química Selva Aída Eidelstein (nono relato) relembra o empregado Rafael: "Mi hija menor, Paula, lo adoraba, apenas abría los ojos en la mañana lo llamaba muy fuerte ;Rafaaaeeel! Él contestaba desde la escalera, iiuju!!! Minina Paula!!! Y a los dos minutos, le traía la bandeja con el desayuno" (p. 108). A paisagista Moira Lavandeiros de Tohá (vigésimo segundo relato) reencontrou anos depois seu ex-cozinheiro Francisco, já idoso à época de serviço, engraxando sapatos na rua: "Fue un 
emotivo encuentro que me permitió volver a constatar su grandeza; no se quejó ni me pidió nada" (p. 200). Estes apontamentos podem dar margem de crítica por parte, entre outros, dos defensores do regime pinochetista, que acusavam chilenos e chilenas de viverem "exílio dourado". No entanto, há que se levar em conta que a estabilidade social dos cooperantes (com traços burgueses, é certo) fez parte do jogo político do presidente Samora Machel que permitiu a presença desses técnicos por anos, e mesmo décadas, na construção do país.

Entrevistados e entrevistadas fazem elogios ao presidente, reconhecendo seu empenho pela manutenção do Estado. Claudio Contreras (quarto relato) diz que Samora, em seus discursos, "también agradecía a los 'cooperantes'y cuando se acordaba de los chilenos, agradecía en español" (p. 08). Tal proximidade com o poder político moçambicano evidencia certo status dos exilados e exiladas no país, porém não formou necessariamente uma elite estrangeira no seio do Estado pois não era permitido aos cooperantes participarem de certas reuniões, como aconteceu no relato do contador Mario Galetovic (décimo segundo relato) sobre a conferência encerrada aos estrangeiros e a continuidade do chileno entre os moçambicanos (p. 137).

Por outro lado, nas memórias sobre Samora Machel há vozes dissonantes, como a dos músicos Carlos Schugurenski (trigésimo sétimo relato), que se "sorprendió" com o fato de Samora ter assinado com a África do Sul o Acordo de Nkomati em 1984 (p. 324), e Juan Antonio Sánchez (trigésimo terceiro relato), que viu como um problema a hierarquização nos círculos de poder: "La cosa se puso un poco sospechosa cuando al tiempo cambió el uniforme por una chaqueta llena de medallas y fue nombrado 'Marechal' (mariscal) y se prohibió que la gente se llamara entre si 'camaradas'. Ahora 'Camaradas' era solo los miembros del partido (Frelimo), y el resto eran 'compañeros"' (p. 285). Da mesma forma, não há consenso sobre as justificativas para a morte do presidente. Reproduzimos a seguir alguns pareceres, para evidenciar como as explicações oscilam entre o silêncio e a acusação: Sergio Basulto (primeiro relato): "accidente aéreo" (p. 36); Mario Galetovic (décimo segundo relato): "muy probablemente provocado" (p. 136); Arturo Hein (vigésimo relato): "desaparecimiento del Presidente" (p. 184); Horacio Romero (trigésimo primeiro relato): "el asesinato del Presidente" (p. 271), "Nunca se ha sabido a ciencia cierta qué ocurrió, pero el hecho es que fue un atentado organizado por África del Sur y el objetivo fue perjudicar a Mozambique; y lo consiguió plenamente” (p. 273); Tegualda Monreal (quadragésimo quinto relato): "el Presidente al que lo mataron" (p. 390).

Alguns testemunhos tentam amenizar os problemas vividos com os moçambicanos. O veterinário Sergio Basulto (primeiro relato) foi interrogado por fazer mediações entre portugueses e moçambicanos, acossado por residir em habitação solicitada pelos militares para evento do Frelimo, e teve um filho de 10 anos detido por fazer graça a um carro oficial (p. 37-38). Sobre a detenção e interrogatório do médico, o próprio presidente Samora Machel minimizou o evento: “'bueno', me dijo, 'seguramente habría sido peor con Pinochet" (p. 40). Sergio afirma que tudo foi "Un gran susto para él [el hijo] que ahora solo genera sonrisas" (p. 38). Se por um lado Jaime Tohá (trigésimo oitavo relato), engenheiro florestal, relembra a "amistad y armonía [...] espíritu unitario [y] poco tiempo para promover conflicto" entre os exilados e exiladas (p. 331), o enfermeiro Abel Ull (trigésimo nono relato) relembra a desconfiança dos concidadãos e concidadãs em relação a ele pois havia chegado de Moçambique diretamente do Chile, podendo ser visto como um agente pinochetista infiltrado (p. 340).

Outras vozes mais críticas dão seu parecer sobre a experiência vivida em Moçambique. Wenke Adam (quadragésimo primeiro relato) relembra criticamente as "consignas políticas triunfalistas", como "Anos oitenta: a década de acabar com o subdesenvolvimento", e o "exceso de ingenuo 
optimismo" na propaganda política da Frelimo (p. 354). Leo Claros C. (segundo relato) afirma que haviam crianças "acostumadas" com prisões e desentendimentos com militares:

(...) cada uno de nosotros había pasado, más de alguna vez, por una detención nocturna, fuera por violación de toque de queda, malinterpretación de las leyes, sospechas de ser espías sudafricanos, falsificación de documentos de identidad y hasta algún juicio popular, cuya condena ninguna de las autoridades sabía cómo hacer cumplir a unos menores de edad blancos y, más encima, chilenos (p. 52$53)$.

$\mathrm{O}$ relato da desenhista gráfica Cristina Pacheco (vigésimo sétimo relato) expõe uma série de arbitrariedades de militares moçambicanos que vai na contramão dos relatos que tentam limitar as tensões vividas entre cooperantes e africanos. Assim, Cristina relembrou a perseguição política ao argentino Jorge Reyna, montonero, e à própria autora, do Movimiento de Izquierda Revolucionario (MIR), presa por escrever slogans oficiais em um resto de comida ao final de refeição, absurda detenção resultante da "vigilância popular" dos moçambicanos (p. 237-241). Passa-se a impressão que as esquerdas adeptas da luta armada tinham tratamento diferenciado em relação aos comunistas chilenos no país, no geral defensores da democracia formal.

Rodrigo Gonçalves (décimo sétimo relato), cineasta chileno, tem um dos relatos mais contrastantes com os demais publicados, pois, além de se referir ao período posterior a Samora Machel, traz algumas denúncias contra uma elite que monopolizava a produção fílmica no país. Gonçalves sustenta que seu sócio Haroon Patel havia sido enviado a uma "operaçâo produçâo", que na prática era um "campo de reeducaçâo" comum em regimes autoritários para afastar intelectuais oposicionistas (p. 162) e que um grupo de cineastas, privilegiados desde a Independência, buscavam impedir que o cineasta tivesse laços com institutos nacionais de cinema e televisão para produções diversas por meio de produtora independente (p. 162-163). Os contatos com Moçambique só foram retomados após 2011, para recuperar acervo fílmico abandonado no país: "La mayor parte del material filmico histórico que existía estaba en completo abandono, destruyéndose lentamente" (p. 164).

Os relatos críticos expõem as ambiguidades da memória nas relações entre chilenos/chilenas e moçambicanos/moçambicanas, tema que necessita de mais e mais investigações para aproximarmos as histórias de América Latina e África. Assim sendo, o livro apresenta-se como uma grande contribuição para os estudos sobre a circulação internacional de exilados e exiladas, a organização do Estado nacional após séculos de exploração colonial e as trocas simbólicas e as tensões entre latino-americanos e africanos. 